\title{
HDL-Mediated Protection of Coronary Vasodilator Response to Adenosine in the Hypercholesterolemic Swine
}

\author{
Federico Vozzi ${ }^{1}$, Gualtiero Pelosi ${ }^{*}$, Mariarita Puntoni1 ${ }^{1}$, Federica Viglione ${ }^{1}$, \\ Silvia Rocchiccioli' ${ }^{1}$, Claudia Kusmic ${ }^{1}$, Fabio Bernini², Paolo Marraccini' ${ }^{1}$, \\ Maria Giovanna Trivella ${ }^{1}$, Oberdan Parodi $^{1}$ \\ ${ }^{1}$ Institute of Clinical Physiology IFC-CNR, Pisa, Italy \\ ${ }^{2}$ Sant'Anna School of Advanced Studies, Pisa, Italy \\ Email: ${ }^{*}$ pelosi@ifc.cnr.it
}

Received 30 September 2014; revised 23 October 2014; accepted 23 November 2014

Copyright (C) 2014 by authors and Scientific Research Publishing Inc.

This work is licensed under the Creative Commons Attribution International License (CC BY). http://creativecommons.org/licenses/by/4.0/

cC) (7) Open Access

\section{Abstract}

It is known that high-cholesterol diet impairs coronary vasodilatation in animal models of atherosclerosis irrespective of overt pathology. We evaluated the specific role of LDL and HDL on adenosine-elicited coronary vasodilatation after short time (10 weeks) high-cholesterol diet in pigs. Nineteen pigs on standard (C), atherogenic (HF) and alternate standard or atherogenic diet every other week (IHF) underwent left coronary angiography and flow (CFR) measurement during intracoronary adenosine injection. Total cholesterol, HDL, LDL, Apo lipoprotein A-1, IL-6, TNF- $\alpha$ and ICAM-1 were measured and histology of coronary samples was performed. IHF and HF show comparable intimal thickening of lesions, similar cholesterol $(598.4 \pm 198.2$ and $633.2 \pm 83.5$ $\mathrm{mg} / \mathrm{dL}$ ) and LDL (502.6 \pm 193.7 and $576.1 \pm 83.2)$, while HDL is double in IHF group (88.3 $\pm 6.4 \mathrm{vs}$ $46.4 \pm 18.7 \mathrm{p}<0.0001$ ). Vasodilation is reduced in HF (CFR $=1.6 \pm 0.2, p<0.001$ ) as compared to $C$ $(2.6 \pm 0.4)$, whilst it is preserved in IHF $(2.7 \pm 0.4)$. CFR and HDL values of all hypercholesterolemia cases are positively correlated $(r=0.88, p<0.001)$. No relation with cytokines/cell adhesion markers is present. These findings suggest for the first time that elevation of plasma HDL level counteracts LDL related vasodilation impairment during coronary atherogenesis in swine.

\section{Keywords}

CFR, HDL, Hypercholesterolemia, Adenosine

\section{Introduction}

The effect of hypercholesterolemia (total cholesterol and its lipoprotein fractions) on coronary microvascular "Corresponding author.

How to cite this paper: Vozzi, F., et al. (2014) HDL-Mediated Protection of Coronary Vasodilator Response to Adenosine in the Hypercholesterolemic Swine. Open Journal of Molecular and Integrative Physiology, 4, 49-61. 
function and anatomy has been investigated in many former [1]-[6] as well as recent studies [7]-[11], both in vitro and in vivo, and the swine animal model of diet-induced hypercholesterolemia has been frequently adopted to reproduce human atherosclerotic disease and/or metabolic syndrome. The great interest for this issue, originated from previous clinical evidence that endothelial-dependent vasodilation as well as pharmacological (adenosine mediated) and metabolic coronary reserve of atherosclerotic-free or non flow-limiting atherosclerotic vessels at angiography, was reduced in hypercholesterolemic patients [12] [13] and could be normalized with the use of cholesterol-lowering strategies or NO donors [14]-[19]. Although a different contribution of total, LDL and HDL cholesterol to the impairment of coronary reserve was evidenced from previous experimental studies, they demonstrated an inhibitory effect of oxidized LDL and a protective role of HDL only on endothelium-dependent arterial vasodilation [20], concordant with clinical observations [21] [22]. On the other hand, the interplay between LDL and HDL and the association with other circulatory factors (cytokines, cell adhesion molecules) in coronary microvascular dysfunction are still partly unexplored. Cholesterol-supplemented high fat diet is a validated method to induce coronary and peripheral artery pathologic changes in the swine model of atherogenesis [23]-[25]. The amount and type of fat intake, even independently of cholesterol addition, is known to induce different anatomical and functional alterations at micro and macrovascular coronary level and a number of diet related factors have been shown to alter the amount of cholesterol carried in plasma LDL and HDL fractions and to drive their distinctive effects on coronary arteriolar vasodilator function [26]-[29].

In this study we aimed to evaluate the effect of plasma lipoprotein profile, modified by a different timing of cholesterol supplemented diet, on coronary vasodilator capability in-vivo, as assessed by coronary pressure-flow measurements during intracoronary adenosine injection and on the extent of early stage artery disease.

\section{Methods}

\subsection{Animals, Diet and Experimental Protocol}

The protocol has been performed in 21 castrated male domesticpigs ( 3 months old, body weight 23 - $46 \mathrm{~kg}$ ). The animals were allocated into three groups: controls on standard diet ( $C, n=7$, body weight $31 \pm 2 \mathrm{~kg}$ ); animals fed daily on cholesterol supplemented high fat diet (HF, $\mathrm{n}=7$, body weight $36 \pm 1 \mathrm{~kg}$ ); pigs on alternate diet, fed on either standard or cholesterol supplemented high fat diet every other week (IHF, $n=7$, body weight $42 \pm$ $2 \mathrm{~kg}$ ) [30]. Diet duration in all groups was $68 \pm 8$ days and the pigs were fed three times a day. Mean baseline body weight in the three groups at baseline was not significantly different.

Standard diet $(4.2 \%$ vegetable fat, $15 \%$ proteins, $54 \%$ carbohydrates, $4.8 \%$ fibres, $22 \%$ vitamins minerals moisture) has been administered for 10 weeks to control animals (C).

High lipid diet (27\% fat - 4\% cholesterol, $20 \%$ lard, 3\% oil - 17.5\% proteins, 33\% carbohydrates, $7 \%$ fibres, $15.5 \%$ vitamins minerals and moisture, $1.5 \%$ Na Cholate) has been administered to HF animals for 10 weeks consecutively. In IHF animals, the same diet has been administered every other week for 10 weeks.

Total energy from standard diet was $3170 \mathrm{Kcal} / \mathrm{kg}$ with Fatty Energy of $378 \mathrm{Kcal}, 12 \%$ of total energy. Total energy from hypercholesterolemic diet was $4450 \mathrm{Kcal} / \mathrm{kg}$ with Fatty Energy of $2430 \mathrm{Kcal}, 54.6 \%$ of total energy.

The anesthesia has been induced by intramuscular administration of $10 \mathrm{mg} / \mathrm{kg}$ of Zoletil ${ }^{\circledR}$ and $0.05 \mathrm{mg} / \mathrm{kg}$ of atropine and maintained with gas (isofluorane, nitrous oxide and oxygen) together with $5 \mathrm{mg} / \mathrm{kg} / \mathrm{h}$ of propofol intravenous infusion. Animals were mechanically ventilated (respiratory volume: $150 \mathrm{ml} / \mathrm{kg} / \mathrm{min}$, respiratory rate: 15 cycles/min). The last day of the last high-fat diet week corresponded to the final acute experiment.

Coronary angiography and coronary pressure-flow measurements were performed in all except two HF cases could not complete the hemodynamic study with pressure-flow assessment due to incurring fatal cardiac arrhythmias during angiography.

Under anesthesia, a guide catheter was advanced into the ostium of left main coronary artery (LMCA) throughout an introducer placed into the left carotid artery. Standardized projections have been used for image acquisitions, which have been set at 15 frames/sec with the magnification commonly used for coronary angiography (Cardio 945, SIAS, Bologna, Italy). The distance source of detector was $97 \mathrm{~cm} .3-7 \mathrm{ml}$ of contrast liquid was injected and images obtained with an X-ray system. Biplane X-ray coronary angiography (RAO 20 2 LAO $20^{\circ}$ ) was performed to confirm catheter position in artery. Pressure and flow measurements have been obtained by coronary Doppler flow velocimetry catheter (ComboMap System, Volcano Corporation, San Diego, CA, USA) which can run the two values with a single probe. The catheter was positioned in the proximal portion of left 
anterior descending artery (LAD) upstream the first diagonal branch under angiography control, for monitoring and recording. To asses microcirculatory vasodilator function, a supramaximal dose of adenosine (3 $\mathrm{mg}$ ) was administered as an intracoronary bolus of $1 \mathrm{ml}$, slowly injected through the Doppler flow-pressure catheter guide; 3 injections were repeated at 20 min interval to ensure maximal flow response assessment. Values of pressure and flow, under baseline condition and during adenosine injection, were recorded. Only stable recordings, free of ectopic beats and/or arrhythmias, with well-defined blood flow velocity pattern for at least 30 seconds, have been utilized for flow measurements. Coronary Flow Reserve (CFR), as an index of the vasodilator response of LAD-dependent territory to intracoronary adenosine injection, is calculated as the ratio between Average Peak Velocity (APV) recorded after adenosine injection and that of baseline pre-injection state. APV values are also normalized for inter-animal and inter-groups coronary pressure differences and an arbitrary coronary resistance index (CRI) was calculated, equal to Mean Coronary Pressure/APV (mmHg/cm/sec).

For heart rate data acquisition, signals were collected by a Gould amplifier (Gould TA 5000, Cleveland, OH, USA) and elaborated by Pulse Viewer, an in-house developed software. Controls and diet-treated animals have been sacrificed after completion of the hemodynamic study by $\mathrm{KCl}$ i.v. bolus injection.

Animal instrumentation and experimental protocol were approved by the Animal Care Committee of the Italian Ministry of Health (Protocol number: 06/2009-B-2009/01/26) according with the Italian Law (DL-116, Jan. 27, 1992) and National Institute of Health Guide for the Care and Use of Laboratory Animals.

\subsection{Histology}

At the end of the in-vivo study the entire heart was excised, washed in isotonic physiologic solution, examined macroscopically and immersed in 10\% buffered formalin for tissue fixation ( 7 - 10 days). Thereafter, arterial samples were harvested from the fixed heart: transverse segments were obtained from left main coronary artery (1 segment of about $10 \mathrm{~mm}$ ), LAD (6 - 7 segments of $10 \mathrm{~mm}$ ) and left circumflex artery (3 segments of $10 \mathrm{~mm}$ ) for routine histologic processing and paraffin embedding. After standard Haematoxylin and Eosin, Weigert van Gieson (elastic laminas) and Mallory trichrome (collagen) staining, consecutive sections from each coronary segment were examined under light microscopy (Olympus BX43, Olympus, Milan, Italy) from $2 \times$ to $40 \times$ original magnification and digitized by a video system (Olympus DP20 camera, Olympus, Milan, Italy) interfaced to a computer with dedicated software (CellSens Dimension, Olympus, Milan, Italy) for image acquisition and morphometric analysis. Pathologic changes of the coronary wall were classified according to Stary stages of atherosclerotic lesions [31] and morphometric indexes (maximal intimal thickness, IT and maximal intimal to media thickness ratio, IMT) assessed as the mean value of 5 consecutive cross sections.

\subsection{Biohumoral Measurements}

Total cholesterol, High Density Lipoprotein (HDL), triglycerides (TG), albumin, glucose, aspartate aminotransferase (ALT) and alanine aminotransferase (AST) were measured by standard enzymatic techniques (Synchron CX9 Pro, Beckman Coulter Inc., Fullerton, CA, USA); Low density lipoprotein (LDL) was calculated according to Friedewald et al. [32], Apolipoprotein A1 has been measured by rate nephelometry (BN-ProSpec, Siemens Healthcare Diagnostics, Milan, Italy). Leukocytes and haematocrit were quantified with ADVIA 2120 Haematology System (Siemens Healthcare Diagnostics, Milan, Italy).

Analysis of total and fractional GGT was performed, as previously described [33] [34], on plasma-ethylenediamine-tetra-acetic acid samples using a fast protein liquid chromatography system (AKTA purifier, GE Healthcare Europe, Milan, Italy) equipped with a gel-filtration column (Superose 6 HR 10/300 GL; GE Healthcare Europe, Milan, Italy) and a fluorescence detector (Jasco FP-2020; Jasco Europe, Lecco, Italy).

IL-6, TNF- $\alpha$ and ICAM-1 were purchased by Abcam (Cambridge, UK), while oxidized LDL (oxLDL) was a product of Antibodies-Online (Atlanta, GA, USA).

\subsection{Statistical Analysis}

End-diet measurements include 7 controls, 5 HF and 7 IHF pigs. Statistical comparison of the three groups has been performed using ANOVA with Fisher LSD test. Linear regression analysis was also used when appropriate.

Data are expressed as means \pm SD (standard deviation) and $\mathrm{p}<0.05$ is considered as statistically significant. 


\section{Results}

\subsection{Biohumoral Variables}

Bio-humoral profile of all cases of the three experimental groups is summarized in Table 1.

High fat diet-treated cases, besides markedly increased plasma lipid levels, show also significantly higher mean values of hematocrit (HF), albumin (HF and IHF) and AST (HF), though with a wide intra group variability. Greater intra group variations are also present in inflammatory markers and ICAM-1 average values, without statistically significant differences among groups.

\subsection{Lipids and Inflammation Markers}

Eight weeks high-fat diet induced significantly higher level of total cholesterol ( $p<0.0001)$, LDL (p < 0.0001), Apo lipoprotein A1 ( $<$ 0.0005) and oxLDL in HF and IHF as compared to C (Table 1), but no significant difference between HF and IHF groups (Table 1).

HDL, Total Cholesterol/HDL and LDL/HDL ratio were significantly higher in IHF and HF as compared to C group. The values of oxLDL comply with the marked increase of LDL, both in IHF and in HF diet-treated group. IHF cases showed a HDL concentration about double that of HF cases and a markedly lower Total Cholesterol/HDL ratio. Inflammatory markers and ICAM-1 displayed a marked intra-group variability with no statistical inter-group difference.

\subsection{Histologic Characterization}

In both HF and IHF groups, initial coronary lesions Type I to III (according to Stary stages [35] or early preatherosclerotic lesions according to Virmani [36]), were observed at histology (Figure 1).

Frequency distribution and morphometric data (mean intimal thickness and mean intima to media thickness ratio) of all lesions are summarized in Table 2.

Despite a comparable global incidence of lesions and despite similar average intimal thickness and intima to media thickness ratio, a relatively more advanced stage of coronary lesions is evidenced in HF relative to IHF cases (higher Stary type III and lower type I lesions incidence).

\subsection{Coronary Imaging and Hemodynamic}

Coronary angiography in C group showed normal coronary vessel profile and diameter without any abnormalities. After 10 weeks diet, none of the 12 pigs treated by high fat diet showed LAD lumen reduction $>10 \%$ at coronary angiography examination. Left coronary angiography evidenced mild irregularities of the coronary profile in 4/5 HF cases and a similar degree of lumen defects in all IHF cases (Figure 2).

A typical tracing of coronary pressure and flow recorded during intracoronary adenosine injection is shown in Figure 3 and hemodynamic results of all cases are reported in Table 3 as average and SD of the three experimental groups at baseline and during adenosine injection.

Table 3 summarizes all hemodynamic parameters measured during end-diet hemodynamic study. Average values of systolic and diastolic coronary pressure and heart rate are higher, though not significantly, in HF and IHF respect to $\mathrm{C}$ group both in baseline conditions and during adenosine administration. Doppler flow velocity measurements in the LAD evidence similar baseline but significantly lower values of APV at maximal adenosine-elicited vasodilation in HF as compared to IHF and C groups. CRI (Mean Pressure/APV, mmHg/cm/sec) mean value, as an index of resistance in LAD-dependent microvasculature, is similar at baseline in all three groups and significantly lower during adenosine injection in IHF and C, but not in HF cases.

As a consequence of these different effects on LAD flow velocity also CFR ratio, as an index of adenosine related increment of myocardial perfusion, is significantly lower in HF compared to IHF group ( $p<0.001)$.

\subsection{Correlations between Lipids/Lipoproteins and Coronary Hemodynamic Findings}

CRI and CFR values during adenosine injection were correlated to the corresponding HDL concentration of each IHF and HF case (Figure 4) and statistically significant linear relations could be demonstrated for pooled data $(\mathrm{p}=0.001, \mathrm{r}=-0.918$; and $\mathrm{p}=0.001, \mathrm{r}=0.878$ respectively)

Moreover, a statistical inverse correlation between CFR and Total Cholesterol/HDL ratio was also evidenced 
Table 1. Biohumoral data of control group (C), high-fat diet group (HF) and alternate high-fat diet group (IHF). Data are reported as mean $( \pm S D)$. LDL cholesterol has been estimated by the Friedewald formula. Statistical analysis: ANOVA followed by Fisher LSD test; ns, not significant.

\begin{tabular}{|c|c|c|c|c|c|c|}
\hline \multirow{2}{*}{ Biohumoral markers } & \multicolumn{3}{|c|}{ Groups } & \multicolumn{3}{|c|}{$\mathrm{p}$} \\
\hline & $\mathrm{C}(7)$ & HF (7) & IHF (7) & C vs HF & C vs IHF & HF vs IHF \\
\hline Total Cholesterol (mg/dL) & $63.3 \pm 4.2$ & $633.2 \pm 83.6$ & $598.4 \pm 198.2$ & $<0.0001$ & $<0.0001$ & ns \\
\hline HDL Cholesterol (mg/dL) & $25.8 \pm 3.8$ & $46.4 \pm 18.7$ & $88.3 \pm 6.4$ & 0.016 & $<0.0001$ & $<0.0001$ \\
\hline LDL Cholesterol (mg/dL) & $27.5 \pm 3.0$ & $576.1 \pm 83.2$ & $502.6 \pm 193.7$ & $<0.0001$ & $<0.0001$ & ns \\
\hline Total Cholesterol/HDL ratio & $2.5 \pm 0.3$ & $15.2 \pm 5.0$ & $6.7 \pm 2.0$ & $<0.0001$ & 0.045 & 0.0003 \\
\hline LDL/HDL ratio & $1.1 \pm 0.2$ & $14.0 \pm 5.0$ & $5.6 \pm 2.0$ & $<0.0001$ & 0.032 & 0.0003 \\
\hline Apolipoprotein A1 (mg/dL) & $25.1 \pm 5.0$ & $61.7 \pm 13.0$ & $52.6 \pm 4.7$ & $<0.0001$ & $<0.0001$ & ns \\
\hline oxLDL (UI/L) & $5.3 \pm 5.2$ & $31.9 \pm 4.2$ & $28.9 \pm 9.4$ & 0.0002 & 0.0002 & ns \\
\hline Triglycerides (mg/dL) & $50.3 \pm 10.5$ & $54.0 \pm 16.8$ & $33.7 \pm 12.7$ & ns & ns & 0.023 \\
\hline Leukocytes ( $(1000 \mathrm{n} / \mathrm{mL})$ & $12.9 \pm 0.4$ & $14.7 \pm 2.4$ & $15.9 \pm 3.6$ & ns & ns & ns \\
\hline Haematocrit (\%) & $26.3 \pm 2.5$ & $31.6 \pm 4.2$ & $27.8 \pm 1.7$ & 0.013 & ns & 0.038 \\
\hline Glucose (mg/dL) & $72.0 \pm 31.0$ & $90.4 \pm 38.2$ & $65.8 \pm 13.4$ & ns & ns & ns \\
\hline Albumin (g/dL) & $2.0 \pm 0.2$ & $2.6 \pm 0.4$ & $2.5 \pm 0.2$ & 0.009 & 0.019 & ns \\
\hline $\operatorname{AST}^{1}(\mathrm{UL} / \mathrm{L})$ & $29.7 \pm 7.6$ & $92.0 \pm 36.3$ & $47.4 \pm 10.0$ & $<0.0001$ & ns & 0.003 \\
\hline $\operatorname{ALT}^{2}(\mathrm{UI} / \mathrm{L})$ & $51.2 \pm 5.0$ & $52.0 \pm 7.0$ & $53.6 \pm 13.0$ & ns & ns & ns \\
\hline $\mathrm{GGT}^{3}(\mathrm{UI} / \mathrm{L})$ & $69.5 \pm 27.3$ & $81.6 \pm 27.4$ & $50.1 \pm 33.7$ & ns & ns & ns \\
\hline ICAM-1 (ng/mL) & $750.1 \pm 314.5$ & $812.1 \pm 141.2$ & $789.6 \pm 236.7$ & ns & ns & ns \\
\hline IL-6 (pg/mL) & $9.2 \pm 18.4$ & $71.4 \pm 124.7$ & $79.8 \pm 110.6$ & ns & ns & ns \\
\hline TNF- $\alpha(\mathrm{pg} / \mathrm{mL})$ & $1251.1 \pm 1320.2$ & $622.0 \pm 1181.9$ & $566.6 \pm 988.6$ & ns & ns & ns \\
\hline
\end{tabular}

${ }^{1} \mathrm{AST}$, aspartate amino transferase, ${ }^{2} \mathrm{ALT}$, alanine amino transferase, ${ }^{3} \mathrm{GGT}$, gamma-glutamyltransferase.

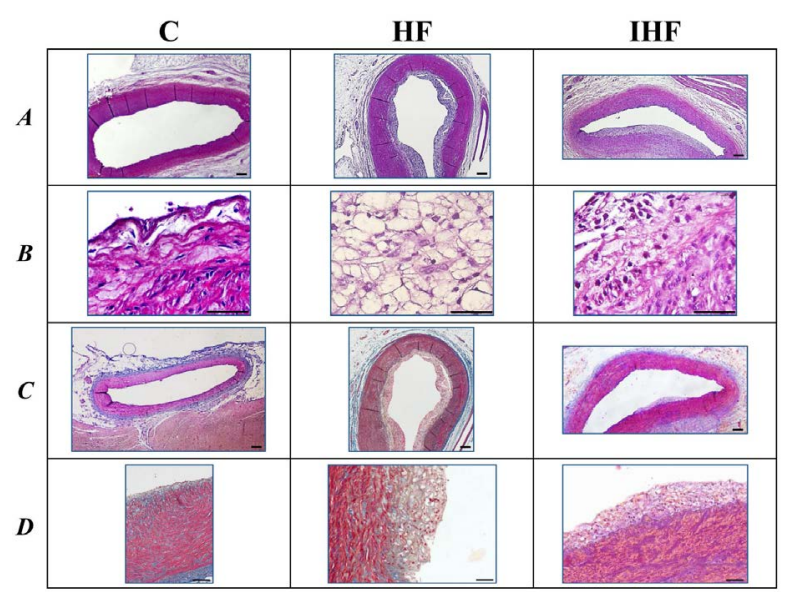

Figure 1. Histopathology of the left main coronary artery (proximal segment) in typical cases of C, HF and IHF groups. Intact intima is present in C. Typical type II lesions (fatty streak) in the two diet-treated groups groups are shown in $\mathrm{H} \& \mathrm{E}$ at low ( $2 \times$ magnification, A, scale bar $200 \mu \mathrm{m})$ and high power (40× magnification, B, scale bar $20 \mu \mathrm{m})$ and in Mallory stained sections (C and D, 2× and 10× original magnification respectively, scale bar 200 and $50 \mu \mathrm{m}$ respectively).

both in all high-cholesterol diet treated cases as well as in all pigs, controls included (Figure 5).

A significant correlation with HDL values is also present in diet-treated pooled cases when APV values instead of CFR values are considered, suggesting a direct effect of HDL concentration also on absolute coronary flow velocity levels reached during adenosine administration (Figure 6).

On the other hand, no significant correlations between any hemodynamic parameter (CRI, CFR and APV) and inflammatory markers (IL-6, TNF- $\alpha$ ) or ICAM-1 could be evidenced. 
Table 2. Frequency distribution of coronary changes, reported as lesion Stary stage and average values (SD) of IT and IMT ratio in HF and IHF groups ( ${ }^{*} \mathrm{p}<0.05$ IHF vs HF).

\begin{tabular}{cccccc}
\hline & \multicolumn{5}{c}{ Groups } \\
\cline { 2 - 6 } & \multicolumn{3}{c}{ HF (7) } & \multicolumn{2}{c}{ IHF (7) } \\
\hline Total segments $\left(\mathrm{n}^{\circ}\right)$ & \multicolumn{2}{c}{72} & \multicolumn{2}{c}{98} \\
Segments with lesions & Nr. & $\%$ & Nr. & $\%$ \\
Type I & 24 & 33,3 & 34 & 35 \\
Type II & 7 & 29 & 18 & $53^{*}$ \\
Type III & 13 & 54 & 16 & 47 \\
Mean Intimal Thickness (IT) $(\mu \mathrm{m})$ & 4 & 17 & 0 & $0^{*}$ \\
Mean Intima/Media Thickness $(\mathrm{IMT})$ ratio & \multicolumn{2}{c}{$205 \pm 120$} & $206 \pm 170$ \\
\hline
\end{tabular}

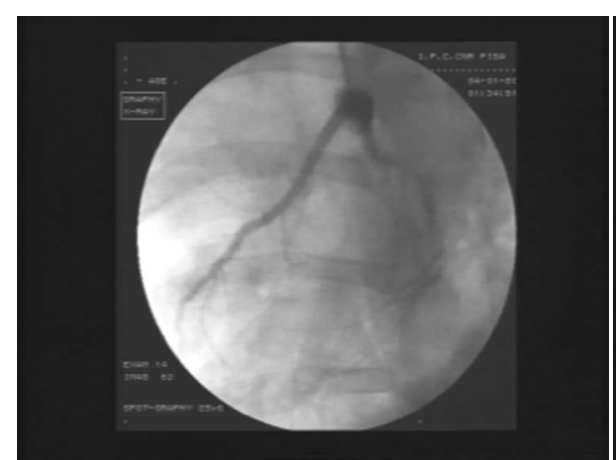

(a)

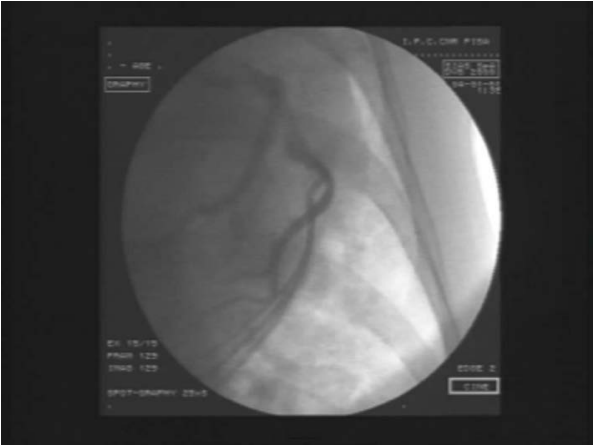

(b)

Figure 2. Example of X-ray angiography image acquisition at $20^{\circ} \mathrm{RAO}(\mathrm{A})$ and $20^{\circ} \mathrm{LAO}(\mathrm{B})$ of $\mathrm{LAD}$ vessel in an HF case.

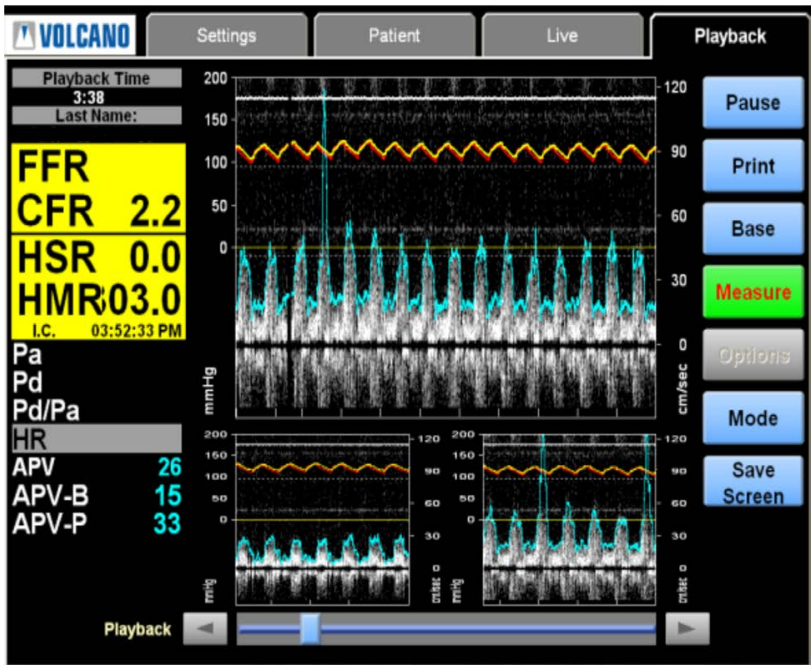

Figure 3. Flow and pressure analysis performed on pigs with ComboMap.

\section{Discussion}

\subsection{Circulatory Lipid/Lipoproteins and Inflammatory Markers}

Cholesterol supplemented high fat diet significantly increases plasma lipids and modifies the concentration of some biohumoral and inflammatory plasma factors.

The different timing of high cholesterol diet supply, either continuous or alternate, has a significant impact on 
Table 3. Coronary hemodynamic parameters evaluated in baseline condition and during adenosine administration. Data are reported as mean (SD). Statistical analysis: ANOVA followed by Fisher LSD test; ns, not significant.

\begin{tabular}{|c|c|c|c|c|c|c|}
\hline \multirow{2}{*}{ Hemodynamic parameters } & \multicolumn{3}{|c|}{ Groups } & \multicolumn{3}{|c|}{$\mathrm{p}$} \\
\hline & C (7) & HF (5) & $\operatorname{IHF}(7)$ & C vs HF & C vs IHF & HF vs IHF \\
\hline Baseline $\mathrm{SP}^{4}(\mathrm{mmHg})$ & $110 \pm 9$ & $120 \pm 11$ & $120 \pm 17$ & ns & ns & ns \\
\hline Adenosine SP (mmHg) & $104 \pm 9$ & $113 \pm 7$ & $118 \pm 17$ & ns & ns & ns \\
\hline Baseline $\mathrm{DP}^{5}(\mathrm{mmHg})$ & $89 \pm 15$ & $102 \pm 9$ & $95 \pm 16$ & ns & ns & ns \\
\hline Adenosine DP (mmHg) & $83 \pm 11$ & $95 \pm 5$ & $91 \pm 15$ & ns & ns & ns \\
\hline Baseline $\mathrm{MP}^{6}(\mathrm{mmHg})$ & $96 \pm 12$ & $108 \pm 8$ & $103 \pm 16$ & ns & ns & ns \\
\hline Adenosine MP (mmHg) & $90 \pm 9$ & $101 \pm 5$ & $100 \pm 16$ & ns & ns & ns \\
\hline Baseline $\operatorname{IPV}^{7}(\mathrm{~cm} / \mathrm{sec})$ & $46 \pm 16$ & $29 \pm 4$ & $33 \pm 9$ & 0.004 & ns & ns \\
\hline Adenosine IPV (cm/sec) & $89 \pm 29$ & $44 \pm 12$ & $72 \pm 11$ & 0.001 & ns & 0.028 \\
\hline Baseline $\mathrm{APV}^{8}(\mathrm{~cm} / \mathrm{sec})$ & $18 \pm 6$ & $15 \pm 2$ & $15 \pm 3$ & ns & ns & ns \\
\hline Adenosine APV $(\mathrm{cm} / \mathrm{sec})$ & $47 \pm 17$ & $24 \pm 4$ & $41 \pm 9$ & 0.002 & ns & 0.023 \\
\hline Baseline $\mathrm{HR}^{9}$ (bpm) & $93 \pm 18$ & $105 \pm 15$ & $100 \pm 21$ & ns & ns & ns \\
\hline Adenosine HR (bpm) & $91 \pm 20$ & $105 \pm 14$ & $97 \pm 18$ & ns & ns & ns \\
\hline Baseline CRI ${ }^{10}(\mathrm{mmHg} / \mathrm{cm} / \mathrm{sec})$ & $5.9 \pm 2.4$ & $7.4 \pm 1.2$ & $7.0 \pm 1.6$ & ns & ns & ns \\
\hline Adenosine CRI (mmHg/cm/sec) & $2.2 \pm 1.0$ & $4.4 \pm 0.8$ & $2.5 \pm 0.5$ & $<0.001$ & ns & $<0.001$ \\
\hline $\mathrm{CFR}^{11}$ & $2.6 \pm 0.4$ & $1.6 \pm 0.2$ & $2.7 \pm 0.4$ & $<0.001$ & ns & $<0.001$ \\
\hline
\end{tabular}

${ }^{4} \mathrm{SP}$, Systolic Pressure; ${ }^{5} \mathrm{DP}$, Diastolic Pressure; ${ }^{6} \mathrm{MP}$, Mean Pressure; ${ }^{7} \mathrm{IPV}$, Instantaneous Peak Velocity; ${ }^{8} \mathrm{APV}$, Average Peak Velocity; ${ }^{9} \mathrm{HR}$, Heart Rate; ${ }^{10} \mathrm{CRI}$, Coronary Resistance Index (calculated as MP/APV ratio); ${ }^{11} \mathrm{CFR}$, Coronary Flow Reserve (calculated as Adenosine APV/Baseline APV ratio).

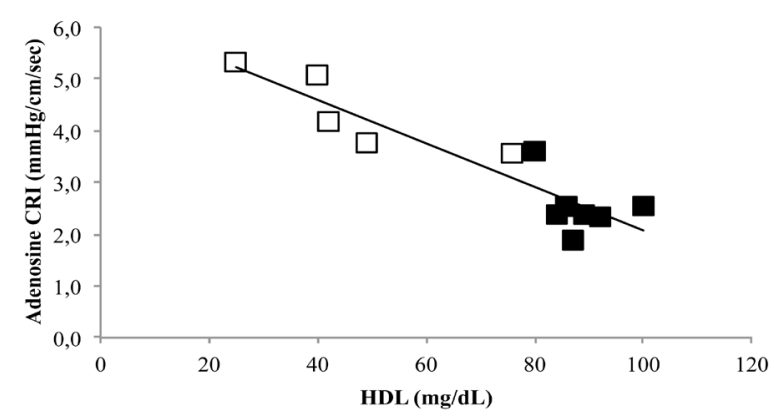

(a)

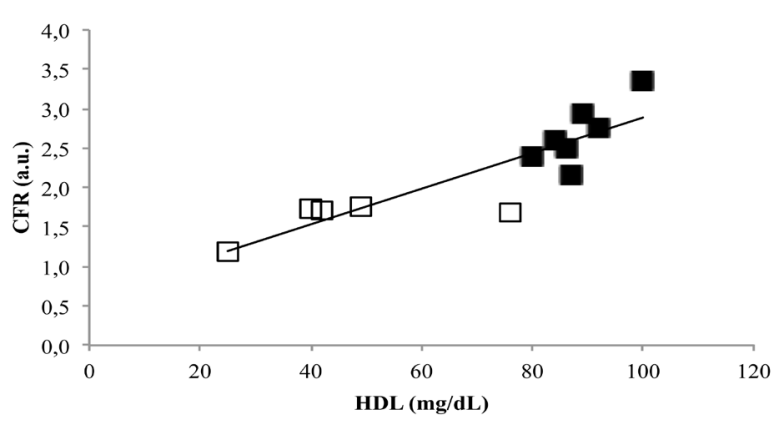

(b)

Figure 4. A. Inverse linear regressions between adenosine CRI vs. HDL concentration in HF ( $\square$ ) and IHF ( $\square$ ) group pooled data ( $\leq \leq 0.001, r=-0.918)$ and B. Direct linear regression between CFR vs. HDL in HF ( $\square$ ) and IHF ( $\square$ ) group pooled data $(\mathrm{p} \leq 0.001, \mathrm{r}=0.878)$.

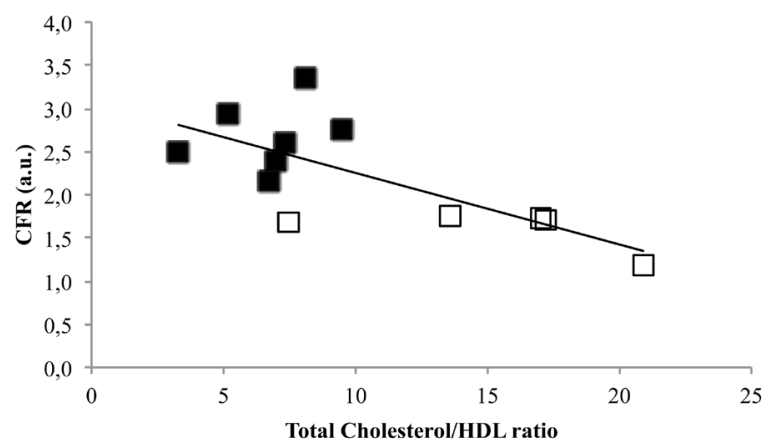

(a)

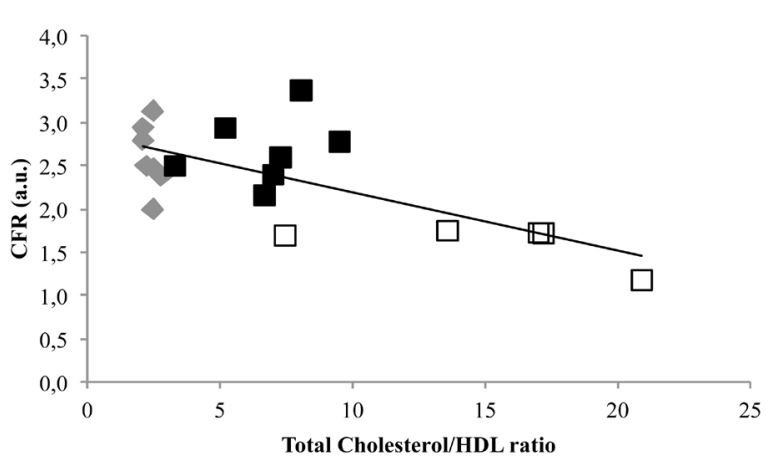

(b)

Figure 5. Linear regression between HDL vs. CFR in HF ( $\square$ ) and IHF ( $\square)$ (A, p=0.008, r= -0.722), and C ( $\mathbf{\square}), \operatorname{HF}(\square)$ and $\operatorname{IHF}(\boldsymbol{\square})$ data group $(\mathrm{B}, \mathrm{p}=0.001, \mathrm{r}=-0.683)$. 


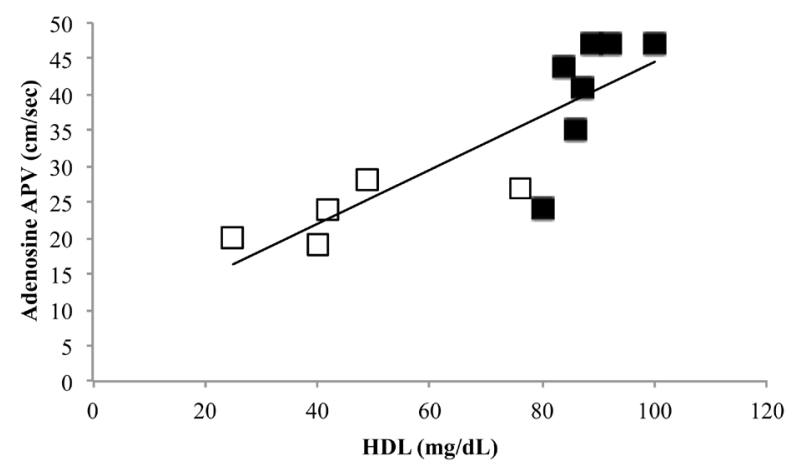

Figure 6. Linear regression between Adenosine APV vs. HDL in HF ( $\square$ ) and IHF ( $\square)$ data group ( $\leq \leq 0.001, r=0.839$ ).

HDL concentration level (about double in IHF, compared to HF cases), on Total Cholesterol/HDL ratio (more than double in HF compared to IHF group) as well as on TG concentration, significantly lower in IHF group.

The amount of circulating LDL is reflected by a higher plasma concentration of oxLDL, with about sixfold increase compared to controls [37]. The same hypercholesterolemic plasma environment accounts for an increased expression of Apolipoprotein A1, especially in HF group, as previously reported [38] [39].

A higher elevation (about tenfold) of total cholesterol and its fractions was observed in our experiments compared to other studies where hypercholesterolemic diets of similar fat and cholesterol composition were used in swine models of atherogenesis [40]. However, reports, where a lower cholesterol supplement for a longer diet period is also able to ensure an almost tenfold LDL elevation [41], suggest that the relation between cholesterol addition to diet, or duration of diet and the increase of total cholesterol and its lipoprotein-fractions in plasma is not direct. In fact, a so high LDL plasma level in this study was reached independently of diet duration, being comparable in HF and IHF groups and it can be likely attributed to liver lipid metabolism adaptations to an excessive cholesterol intake. The same considerations can be done for HDL elevation: a great variability is present in different studies of swine hypercholesterolemia [40] [41]. To clarify these results a primary role of increased hepatic synthesis of HDL in alternate diet regimen and a better adaptation of liver metabolism to plasma lipid overload as compared to continuous cholesterol administration can be reasonably sustained [42]. Regarding systemic inflammatory state and endothelial activation no significant changes among groups were evidenced in any of measured markers, in contrast with other reports [40] [43]-[45]. This outcome can be attributed to the shorttime diet duration and the very early stage of coronary atherogenesis process documented by histology.

The short duration of high cholesterol diet can also account for the minor atheroprotective effect of elevated HDL in IHF group where no a significant difference was observed in overall coronary morph metric indexes despite relatively milder lesion stage.

\subsection{Adenosine-Elicited Coronary Vasodilation and Plasma Lipoprotein Expressions}

Although the protective effect of HDL levels on endothelial-dependent vasodilation in hypercholesterolemia has been reported in humans and animal models [46] [47], no previous experimental studies show a so close relation between adenosine elicited coronary flow response and HDL plasma levels in the hypercholesterolemic swine.

It is known that the major vasodilator effect of adenosine is mediated by direct stimulation of A2-adenosine receptors on vascular smooth muscle cells, through cyclic adenosine monophosphate increase. Although adenosine has been used frequently in animal as well as in human studies to evaluate endothelium-independent vasodilation, it acts also as an endothelial-dependent vasodilator, both through flow-mediated dilation [48] and by direct stimulation of A1-adenosine [49] and other purinergic receptors on endothelial cells. Therefore, impaired vasodilation, as assessed by Doppler flow measurements in proximal LAD during intracoronary adenosine injection, is a measure of both vascular endothelial function and of smooth muscle relaxation. Although adenosine-elicited vasodilation reflects, at least in part, endothelial function, intracoronary adenosine injection should be considered as the only physiologic stimulus able to recruit most of the vasodilator capacity of coronary microcirculatory district in a endothelial-independent way.

In our study, high fat diet is able to modulate the haemodynamic parameters. Mild increases of coronary 
pressure and heart rate are observed both at baseline and during adenosine administration, whilst a markedly lower coronary blood flow velocity is measured in the LAD of HF cases, in response to adenosine, indicating a consistent arteriolar dysfunction. These findings suggest a vasoconstricting effect generated by elevated LDL and oxLDL plasma levels, formerly attributed to abolished $\mathrm{Kv}$ channel contribution to adenosine-mediated relaxation due to its impaired activation [50] as well as by inhibited NO-dependent endothelial function [6] [11].

A generalized vasoconstricting effect of elevated LDL and oxLDL plasma levels could not be excluded and can lead to an increased coronary perfusion pressure and an incorrect estimation of coronary vasodilator response to adenosine when absolute (APV) and relative (CFR ratio) flow velocity measurements are considered. For this reason, a coronary resistance index, i.e. the ratio of mean coronary perfusion pressure to mean coronary flow velocity was adopted as a more adequate estimate of coronary vasodilator function. A significant decrease of CRI is elicited by adenosine injection in IHF, where average HDL concentration is double, but not in HF group, despite similar LDL and oxLDL plasma levels.

Within the limits of the animal model, such as the duration of atherogenic diet, our data support the hypothesis that HDL plasma elevation is able to attenuate hypercholesterolemia related impairment of adenosine mediated metabolic vasodilation, despite supramaximal total, LDL and oxLDL cholesterol plasma levels. This effect is independent of preatherosclerotic changes observed in the epicardial coronary arteries, as HF and IHF cases have comparable histomorphometric features of left coronary artery lesions.

Moreover, HDL plasma concentration seems also able to modulate the extent of coronary arteriolar vasodilatation as suggested by the direct and strong relation between CRI and HDL plasma values within a wide range (from 20 to $100 \mathrm{mg} / \mathrm{dL}$ ) in all high fat diet treated animals. In a previous report, CFR measured after a moderate dose of intracoronary adenosine $(1 \mathrm{mcg} / \mathrm{Kg})$ in hypercholesterolemic Ossabaw pigs resulted unchanged and arteriolar A2B receptors were found reduced, suggesting that the mechanisms mediating coronary arteriolar dilation to adenosine are altered in early-stage metabolic syndrome prior to overt decrements in coronary vasodilator reserve [8]. However, no correlation with HDL levels was presented and the lack of statistical significance of coronary reserve impairment was probably due to the very low dose of intracoronary adenosine injected (100 times lower than in our study).

Moreover, the inverse relation between coronary vasodilator response and Total Cholesterol/HDL ratio in high fat diet treated animals suggests that the relative amount of LDL has a negative impact on adenosine-mediated vasodilation, as reported in previous clinical studies [51].

\subsection{Clinical Implications}

Our observational study supports the view that circulating HDL lipoprotein fraction is a major protective factor of coronary microcirculatory function in hypercholesterolemia.

The protective effect of HDL on both endothelial function and global arteriolar vasodilator capacity is a relevant clinical issue in cardiovascular disease since its potential therapeutic application widens from atherosclerosis [52] to metabolic syndrome [53]-[55] and cardiac failure [56]. HDL therapy has become an emerging area of therapeutic development in the cardiovascular field, aimed at supplementing and improving the vascular benefit exerted by current therapeutic strategies, i.e. extended-release niacin [57], the CETP inhibitors dalcetrapib and anacetrapib [58], reconstituted forms of HDL [59] or apoA-I mimetics [60] that are directed towards preventing the early microcirculatory dysfunction caused by hypercholesterolemia [61].

These observations underscore the role of HDL raising approaches as effective intervention for slowing progression or favoring regression of atherosclerosis.

\section{Conclusions}

In conclusion, key results of this study are:

1) Coronary vasodilator response to adenosine is not impaired despite markedly elevated total cholesterol, LDL and oxLDL plasma levels when a concomitant and disproportionate elevation of the HDL fraction is induced by diet manipulation, in absence of significant inflammation marker changes and at equivalent coronary pathology stage.

2) A strong inverse correlation between adenosine-induced coronary resistance decrease and HDL cholesterol fraction, over a wide range of plasma values, is evidenced in all hypercholesterolemic pigs, suggesting that HDL protection of coronary vasodilator function may be considered concentration-dependent. 


\section{Acknowledgements}

The study was funded by a grant from ARTreat project, FP7-ICT-2007 (grant agreement 224297).

A special thanks goes to Dr. Daniele Panetta for helpful discussion of the results.

\section{References}

[1] Abebe, W. and Mustafa, S.J. (1997) Effect of Low Density Lipoprotein on Adenosine Receptor-Mediated Coronary Vasorelaxation in Vitro. Journal of Pharmacology and Experimental Therapeutics, 282, 851-857.

[2] Rodriguez-Porcel, M., Lerman, A., Ritman, E.L., et al. (2000) Altered Myocardial Microvascular 3D Architecture in Experimental Hypercholesterolemia. Circulation, 102, 2028-2030. http://dx.doi.org/10.1161/01.CIR.102.17.2028

[3] Rodriguez-Porcel, M., Lerman, A., Best, P.J., et al. (2001) Hypercholesterolemia Impairs Myocardial Perfusion and Permeability: Role of Oxidative Stress and Endogenous Scavenging Activity. Journal of the American College of Cardiology, 37, 608-615. http://dx.doi.org/10.1016/S0735-1097(00)01139-6

[4] Theilmeier, G., Verhamme, P., Dymarkowski, S., et al. (2002) Hypercholesterolemia in Minipigs Impairs Left Ventricular Response to Stress: Association with Decreased Coronary Flow Reserve and Reduced Capillary Density. Circulation, 106, 1140-1146. http://dx.doi.org/10.1161/01.CIR.0000026805.41747.54

[5] Mathew, V., Cannan, C.R., Miller, V.M., et al. (1997) Enhanced Endothelin-Mediated Coronary Vasoconstriction and Attenuated Basal Nitric Oxide Activity in Experimental Hypercholesterolemia. Circulation, 96, 1930-1936. http://dx.doi.org/10.1161/01.CIR.96.6.1930

[6] Chen, C.H. and Henry, P.D. (1997) Atherosclerosis as a Microvascular Disease: Impaired Angiogenesis Mediated by Suppressed Basic Fibroblast Growth Factor Expression. Proceedings of the Association of American Physicians, 109, 351-361.

[7] Mannheim, D., Versari, D., Daghini, E., et al. (2007) Impaired Myocardial Perfusion Reserve in Experimental Hypercholesterolemia Is Independent of Myocardial Neovascularization. American Journal of Physiology—Heart and Circulatory Physiology, 292, H2449-H2458. http://dx.doi.org/10.1152/ajpheart.01215.2006

[8] Bender, S.B., Tune, J.D., Borbouse, L., et al. (2009) Altered Mechanism of Adenosine-Induced Coronary Arteriolar Dilation in Early-Stage Metabolic Syndrome. Experimental Biology and Medicine (Maywood), 234, 683-692. http://dx.doi.org/10.3181/0812-RM-350

[9] Heaps, C.L., Jeffery, E.C., Laine, G.A., et al. (2008) Effects of Exercise Training and Hypercholesterolemia on Adenosine Activation of Voltage-Dependent K+ Channels in Coronary Arterioles. Journal of Applied Physiology, 105, 1761-1771. http://dx.doi.org/10.1152/japplphysiol.90958.2008

[10] Borbouse, L., Dick, G.M., Payne, G.A., et al. (2010) Metabolic Syndrome Reduces the Contribution of K+ Channels to Ischemic Coronary Vasodilation. American Journal of Physiology—Heart and Circulatory Physiology, 298, H1182H1189.

[11] Wang, W., Hein, T.W., Zhang, C., Zawieja, D.C., Liao, J.C. and Kuo, L. (2010) Oxidized Low-Density Lipoprotein Inhibits Nitric Oxide-Mediated Coronary Arteriolar Dilation by Up-Regulating Endothelial Arginase I. Microcirculation, 18, 36-45. http://dx.doi.org/10.1111/j.1549-8719.2010.00066.x

[12] Zeiher, A.M., Drexler, H., Wollschläger, H. and Just, H. (1991) Endothelial Dysfunction of the Coronary Microvasculature Is Associated with Coronary Blood Flow Regulation in Patients with Early Atherosclerosis. Circulation, 84, 1984-1992. http://dx.doi.org/10.1161/01.CIR.84.5.1984

[13] Seiler, C., Hess, O.M., Buechi, M., Suter, T.M. and Krayenbuehl, H.P. (1993) Influence of Serum Cholesterol and Other Coronary Risk Factors on Vasomotion of Angiographically Normal Coronary Arteries. Circulation, 88, 21392148. http://dx.doi.org/10.1161/01.CIR.88.5.2139

[14] Drexler, H., Zeiher, A.M., Meinzer, K. and Just, H. (1991) Correction of Endothelial Dysfunction in Coronary Microcirculation of Hypercholesterolaemic Patients by L-Arginine. Lancet, 338, 1546-1550. http://dx.doi.org/10.1016/0140-6736(91)92372-9

[15] Creager, M.A., Gallagher, S.J., Girerd, X.J., Coleman, S.M., Dzau, V.J. and Cooke, J.P. (1992) L-Arginine Improves Endothelium-Dependent Vasodilation in Hypercholesterolemic Humans. Journal of Clinical Investigation, 90, 12481253. http://dx.doi.org/10.1172/JCI115987

[16] Leung, W.H., Lau, C.P. and Wong, C.K. (1993) Beneficial Effect of Cholesterol-Lowering Therapy on Coronary Endothelium-Dependent Relaxation in Hypercholesterolaemic Patients. The Lancet, 341, 1496-1500. http://dx.doi.org/10.1016/0140-6736(93)90634-S

[17] Egashira, K., Hirooka, Y., Kai, H., Sugimachi, M., Suzuki, S., Inou, T. and Takeshita, A. (1994) Reduction in Serum Cholesterol with Pravastatin Improves Endothelium-Dependent Coronary Vasomotion in Patients with Hypercholesterolemia. Circulation, 89, 2519-2524. http://dx.doi.org/10.1161/01.CIR.89.6.2519 
[18] Treasure, C.B., Klein, J.L., Weintraub, W.S., Talley, J.D., Stillabower, M.E., Kosinski, A.S., et al. (1995) Beneficial Effects of Cholesterol-Lowering Therapy on the Coronary Endothelium in Patients with Coronary Artery Disease. New England Journal of Medicine, 332, 481-487. http://dx.doi.org/10.1056/NEJM199502233320801

[19] Anderson, T.J., Meredith, I.T., Yeung, A.C., Frei, B., Selwyn, A.P. and Ganz, P. (1995) The Effect of Cholesterol-Lowering and Antioxidant Therapy on Endothelium-Dependent Coronary Vasomotion. New England Journal of Medicine, 332, 488-493. http://dx.doi.org/10.1056/NEJM199502233320802

[20] Matsuda, Y., Hirata, K., Inoue, N., Suematsu, M., Kawashima, S., Akita, H. and Yokoyama, M. (1993) High Density Lipoprotein Reverses Inhibitory Effect of Oxidized Low Density Lipoprotein on Endothelium-Dependent Arterial Relaxation. Circulation Research, 72, 1103-1109. http://dx.doi.org/10.1161/01.RES.72.5.1103

[21] Bisoendial, R.J., Hovingh, G.K., Levels, J.H.M., Lerch, P.G., Andresen, I., Hayden, M.R., et al. (2003) Restoration of Endothelial Function by Increasing High-Density Lipoprotein in Subjects with Isolated Low High-Density Lipoprotein. Circulation, 107, 2944-2948. http://dx.doi.org/10.1161/01.CIR.0000070934.69310.1A

[22] Kaufmann, P.A., Gnecchi-Ruscone, T., Schäfers, K.P., Lüscher, T.F. and Camici, P.G. (2000) Low Density Lipoprotein Cholesterol and Coronary Microvascular Dysfunction in Hypercholesterolemia. Journal of the American College of Cardiology, 36, 103-109. http://dx.doi.org/10.1016/S0735-1097(00)00697-5

[23] Moghadasian, M.H., Frohlich, J.J. and McManus, B.M. (2001) Advances in Experimental Dyslipidemia and Atherosclerosis. Laboratory Investigation, 81, 1173-1183. http://dx.doi.org/10.1038/labinvest.3780331

[24] Vilahur, G., Padro, T. and Badimon, L. (2011) Atherosclerosis and Thrombosis: Insights from Large Animal Models. Journal of Biomedicine and Biotechnology, 2011, Article ID: 907575.

[25] Busnelli, M., Froio, A., Bacci, M.L., Giunti, M., Cerrito, M.G., Giovannoni, R., et al. (2009) Pathogenetic Role of Hypercholesterolemia in a Novel Preclinical Model of Vascular Injury in Pigs. Atherosclerosis, 207, 384-390. http://dx.doi.org/10.1016/j.atherosclerosis.2009.05.022

[26] Schaefer, E.J., Levy, R.I., Ernst, N.D., Van Sant, F.D. and Brewer Jr., H.B. (1981) The Effects of Low Cholesterol, High Polyunsaturated Fat, and Low Fat Diets on Plasma Lipid and Lipoprotein Cholesterol Levels in Normal and Hypercholesterolemic Subjects. American Journal of Clinical Nutrition, 34, 1758-1763.

[27] Ehnholm, C., Huttunen, J.K., Pietinen, P., Leino, U., Mutanen, M., Kostiainen, E., et al. (1982) Effect of Diet on Serum Lipoproteins in a Population with a High Risk of Coronary Heart Disease. New England Journal of Medicine, 307, 850-855. http://dx.doi.org/10.1056/NEJM198209303071403

[28] Sattler, K.J.E., Galili, O., Rodriguez-Porcel, M., Krier, J.D., Lerman, L.O. and Lerman, A. (2006) Dietary Reversal of Experimental Hypercholesterolemia Improves Endothelial Dysfunction of Epicardial Arteries but Not of Small Coronary Vessels in Pigs. Atherosclerosis, 188, 301-308. http://dx.doi.org/10.1016/j.atherosclerosis.2005.11.009

[29] Artinger, S., Deiner, C., Loddenkemper, C., Schwimmbeck, P.L., Schultheiss, H.P. and Pels, K. (2009) Complex Porcine Model of Atherosclerosis: Induction of Early Coronary Lesions after Long-Term Hyperlipidemia without Sustained Hyperglycemia. Canadian Journal of Cardiology, 25, e109-e114. http://dx.doi.org/10.1016/S0828-282X(09)70068-6

[30] Puccinelli, E., Gervasi, P.G., Trivella, M.G., et al. (2014) Modulation of Lipid Homeostasis in Response to Continuous or Intermittent High-Fat Diet in Pigs. Animal: An International Journal of Animal Bioscience.

[31] Stary, H.C., Chandler, A.B., Glagov, S., Guyton, J.R., Insull Jr., W., Rosenfeld, M.E., et al. (1994) A Definition of Initial, Fatty Streak, and Intermediate Lesions of Atherosclerosis. A Report from the Committee on Vascular Lesions of the Council on Arteriosclerosis, American Heart Association. Circulation, 89, 2462-2478. http://dx.doi.org/10.1161/01.CIR.89.5.2462

[32] Friedewald, W.T., Levy, R.I. and Fredrickson, D.S. (1972) Estimation of the Concentration of Low-Density Lipoprotein Cholesterol in Plasma, without Use of the Preparative Ultracentrifuge. Clinical Chemistry, 18, 499-502.

[33] Franzini, M., Ottaviano, V., Fierabracci, V., Bramanti, E., Zyw, L., Barsacchi, R., et al. (2008) Fractions of Plasma Gamma-Glutamyltransferase in Healthy Individuals: Reference Values. Clinica Chimica Acta, 395, 188-189. http://dx.doi.org/10.1016/j.cca.2008.06.005

[34] Franzini, M., Bramanti, E., Ottaviano, V., Ghiri, E., Scatena, F., Barsacchi, R., et al. (2008) A High Performance Gel Filtration Chromatography Method for Gamma-Glutamyltransferase Fraction Analysis. Analytical Biochemistry, 374, 1-6. http://dx.doi.org/10.1016/j.ab.2007.10.025

[35] Stary, H.C. (2000) Natural History and Histological Classification of Atherosclerotic Lesions: An Update. Arteriosclerosis, Thrombosis, and Vascular Biology, 20, 1177-1178. http://dx.doi.org/10.1161/01.ATV.20.5.1177

[36] Virmani, R., Kolodgie, F.D., Burke, A.P., Farb, A. and Schwartz, S.M. (2000) Lessons from Sudden Coronary Death: A Comprehensive Morphological Classification Scheme for Atherosclerotic Lesions. Arteriosclerosis, Thrombosis, and Vascular Biology, 20, 1262-1275. http://dx.doi.org/10.1161/01.ATV.20.5.1262

[37] Matsuzawa-Nagata, N., Takamura, T., Ando, H., Nakamura, S., Kurita, S., Misu, H., et al. (2008) Increased Oxidative 
Stress Precedes the Onset of High-Fat Diet-Induced Insulin Resistance and Obesity. Metabolism-Clinical and Experimental, 57, 1071-1077. http://dx.doi.org/10.1016/j.metabol.2008.03.010

[38] Schwab, D.A., Rea, T.J., Hanselman, J.C., Bisgaier, C.L., Krause, B.R. and Pape, M.E. (2000) Elevated Hepatic Apolipoprotein AI Transcription Is Associated with Diet-Induced Hyperalphalipoproteinemia in Rabbits. Life Sciences, 66, 1683-1694. http://dx.doi.org/10.1016/S0024-3205(00)00491-4

[39] Onat, A., Hergenç, G., Bulur, S., Uğur, M., Küçükdurmaz, Z. and Can, G. (2010) The Paradox of High Apolipoprotein A-I Levels Independently Predicting Incident Type-2 Diabetes among Turks. International Journal of Cardiology, 142, 72-79. http://dx.doi.org/10.1016/j.ijcard.2008.12.066

[40] Busnelli, M., Manzini, S., Froio, A., Vargiolu, A., Cerrito, M.G., Smolenski, R.T., et al. (2013) Diet Induced Mild Hypercholesterolemia in Pigs: Local and Systemic Inflammation, Effects on Vascular Injury—Rescue by High-Dose Statin Treatment. PLOS ONE, 8, e80588. http://dx.doi.org/10.1371/journal.pone.0080588

[41] Wilson, S.H., Simari, R.D., Best, P.J., Peterson, T.E., Lerman, L.O., Aviram, M., et al. (2001) Simvastatin Preserves Coronary Endothelial Function in Hypercholesterolemia in the Absence of Lipid Lowering. Arteriosclerosis, Thrombosis, and Vascular Biology, 21, 122-128. http://dx.doi.org/10.1161/01.ATV.21.1.122

[42] Puccinelli, E., Gervasi, P.G., Pelosi, G., Puntoni, M. and Longo, V. (2013) Modulation of Cytochrome P450 Enzymes in Response to Continuous or Intermittent High-Fat Diet in Pigs. Xenobiotica, 43, 686-698. http://dx.doi.org/10.3109/00498254.2012.756558

[43] Shrestha, C., Ito, T., Kawahara, K.I., Shrestha, B., Yamakuchi, M., Hashiguchi, T. and Maruyama, I. (2013) Saturated Fatty Acid Palmitate Induces Extracellular Release of Histone H3: A Possible Mechanistic Basis for High-Fat Diet-Induced Inflammation and Thrombosis. Biochemical and Biophysical Research Communications, 437, 573-578. http://dx.doi.org/10.1016/j.bbrc.2013.06.117

[44] Lin, H.L., Shen, K.P., Chang, W.T., Lin, J.C., An, L.M., Chen, I.J. and Wu, B.N. (2013) Eugenosedin-A Prevents High-Fat Diet Increased Adhesion Molecules through Inhibition of MAPK-and p65-Mediated NF- $\kappa$ B Pathway in Rat Model. Journal of Pharmacy and Pharmacology, 65, 300-309. http://dx.doi.org/10.1111/j.2042-7158.2012.01597.x

[45] Fotis, L., Agrogiannis, G., Vlachos, I.S., Pantopoulou, A., Margoni, A., Kostaki, M., et al. (2012) Intercellular Adhesion Molecule (ICAM)-1 and Vascular Cell Adhesion Molecule (VCAM)-1 at the Early Stages of Atherosclerosis in a Rat Model. In Vivo, 26, 243-250.

[46] Nofer, J.R., van der Giet, M., Tölle, M., Wolinska, I., von Wnuck Lipinski, K., Baba, H.A., et al. (2004) HDL Induces NO-Dependent Vasorelaxation via the Lysophospholipid Receptor S1P3. Journal of Clinical Investigation, 113, 569581. http://dx.doi.org/10.1172/JCI200418004

[47] Spieker, L.E., Sudano, I., Hürlimann, D., Lerch, P.G., Lang, M.G., Binggeli, C., et al. (2002) High-Density Lipoprotein Restores Endothelial Function in Hypercholesterolemic Men. Circulation, 105, 1399-1402. http://dx.doi.org/10.1161/01.CIR.0000013424.28206.8F

[48] Zanzinger, J. and Bassenge, E. (1993) Coronary Vasodilation to Acetylcholine, Adenosine and Bradykinin in Dogs: Effects of Inhibition of NO-Synthesis and Captopril. European Heart Journal, 14, 164-168.

[49] Smits, P., Williams, S.B., Lipson, D.E., Banitt, P., Rongen, G.A. and Creager, M.A. (1995) Endothelial Release of Nitric Oxide Contributes to the Vasodilator Effect of Adenosine in Humans. Circulation, 92, 2135-2141. http://dx.doi.org/10.1161/01.CIR.92.8.2135

[50] Heaps, C.L., Tharp, D.L. and Bowles, D.K. (2004) Hypercholesterolemia Abolishes Voltage-Dependent $\mathrm{K}^{+}$Channel Contribution to Adenosine-Mediated Relaxation in Porcine Coronary Arterioles. American Journal of Physiology: Heart and Circulatory Physiology, 288, H568-H576.

[51] Galderisi, M., Capaldo, B., Sidiropulos, M., D’Errico, A., Ferrara, L., Turco, A., et al. (2007) Determinants of Reduction of Coronary Flow Reserve in Patients with Type 2 Diabetes Mellitus or Arterial Hypertension without Angiographically Determined Epicardial Coronary Stenosis. American Journal of Hypertension, 20, 1283-1290. http://dx.doi.org/10.1016/j.amjhyper.2007.08.005

[52] Gordon, D.J., Probstfield, J.L., Garrison, R.J., Neaton, J.D., Castelli, W.P., Knoke, J.D., et al. (1989) High-Density Lipoprotein Cholesterol and Cardiovascular Disease. Four Prospective American Studies. Circulation, 79, 8-15. http://dx.doi.org/10.1161/01.CIR.79.1.8

[53] Leroith, D. (2012) Pathophysiology of the Metabolic Syndrome: Implications for the Cardiometabolic Risks Associated With Type 2 Diabetes. The American Journal of the Medical Sciences, 343, 13-16. http://dx.doi.org/10.1097/MAJ.0b013e31823ea214

[54] Nakou, E.S., Filippatos, T.D., Kiortsis, D.N., Derdemezis, C.S., Tselepis, A.D., Mikhailidis, D.P. and Elisaf, M.S. (2008) The Effects of Ezetimibe and Orlistat, Alone or in Combination, on High-Density Lipoprotein (HDL) Subclasses and HDL-Associated Enzyme Activities in Overweight and Obese Patients with Hyperlipidaemia. Expert Opinion on Pharmacotherapy, 9, 3151-3158. http://dx.doi.org/10.1517/14656560802548430 
[55] Filippatos, T.D., Liberopoulos, E.N., Kostapanos, M., Gazi, I.F., Papavasiliou, E.C., Kiortsis, D.N., Tselepis, A.D. and Elisaf, M.S. (2008) The Effects of Orlistat and Fenofibrate, Alone or in Combination, on High-Density Lipoprotein Subfractions and Pre-beta1-HDL Levels in Obese Patients with Metabolic Syndrome. Diabetes, Obesity and Metabolism, 10, 476-483. http://dx.doi.org/10.1111/j.1463-1326.2007.00733.x

[56] Wedel, H., McMurray, J.J., Lindberg, M., et al. (2009) Predictors of Fatal and Non-Fatal Outcomes in the Controlled Rosuvastatin Multinational Trial in Heart Failure (CORONA): Incremental Value of Apolipoprotein A-1, High-Sensitivity C-Reactive Peptide and N-Terminal Pro B-Type Natriuretic Peptide. European Journal of Heart Failure, 11, 281-291. http://dx.doi.org/10.1093/eurjhf/hfn046

[57] Markel, A. (2011) The Resurgence of Niacin: From Nicotinic Acid to Niaspan/Laropiprant. Israel Medical Association Journal, 13, 368-374.

[58] Sirtori, C.R. (2011) Investigational CETP Antagonists for Hyperlipidemia and Atherosclerosis Prevention. Expert Opinion on Investigational Drugs, 20, 1543-1554. http://dx.doi.org/10.1517/13543784.2011.614946

[59] Chenevard, R., Hürlimann, D., Spieker, L., Béchir, M., Enseleit, F., Hermann, M., et al. (2010) Reconstituted HDL in Acute Coronary Syndromes. Cardiovascular Therapeutics, 30, e51-e57.

[60] Sherman, C.B., Peterson, S.J. and Frishman, W.H. (2010) Apolipoprotein A-I Mimetic Peptides: A Potential New Therapy for the Prevention of Atherosclerosis. Cardiology in Review, 18, 141-147. http://dx.doi.org/10.1097/CRD.0b013e3181c4b508

[61] Stokes, K.Y., Cooper, D., Tailor, A. and Granger, D.N. (2002) Hypercholesterolemia Promotes Inflammation and Microvascular Dysfunction: Role of Nitric Oxide and Superoxide1. Free Radical Biology and Medicine, 33, 1026-1036. http://dx.doi.org/10.1016/S0891-5849(02)01015-8 
Scientific Research Publishing (SCIRP) is one of the largest Open Access journal publishers. It is currently publishing more than 200 open access, online, peer-reviewed journals covering a wide range of academic disciplines. SCIRP serves the worldwide academic communities and contributes to the progress and application of science with its publication.

Other selected journals from SCIRP are listed as below. Submit your manuscript to us via either submit@scirp.org or Online Submission Portal.
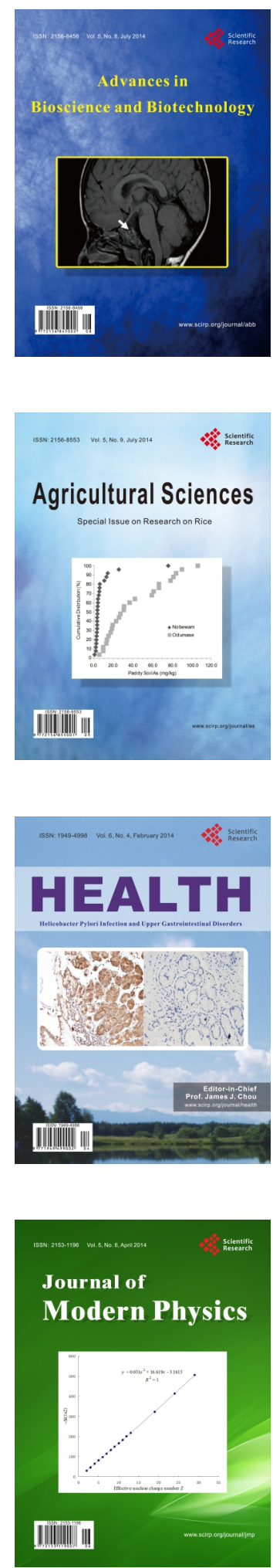
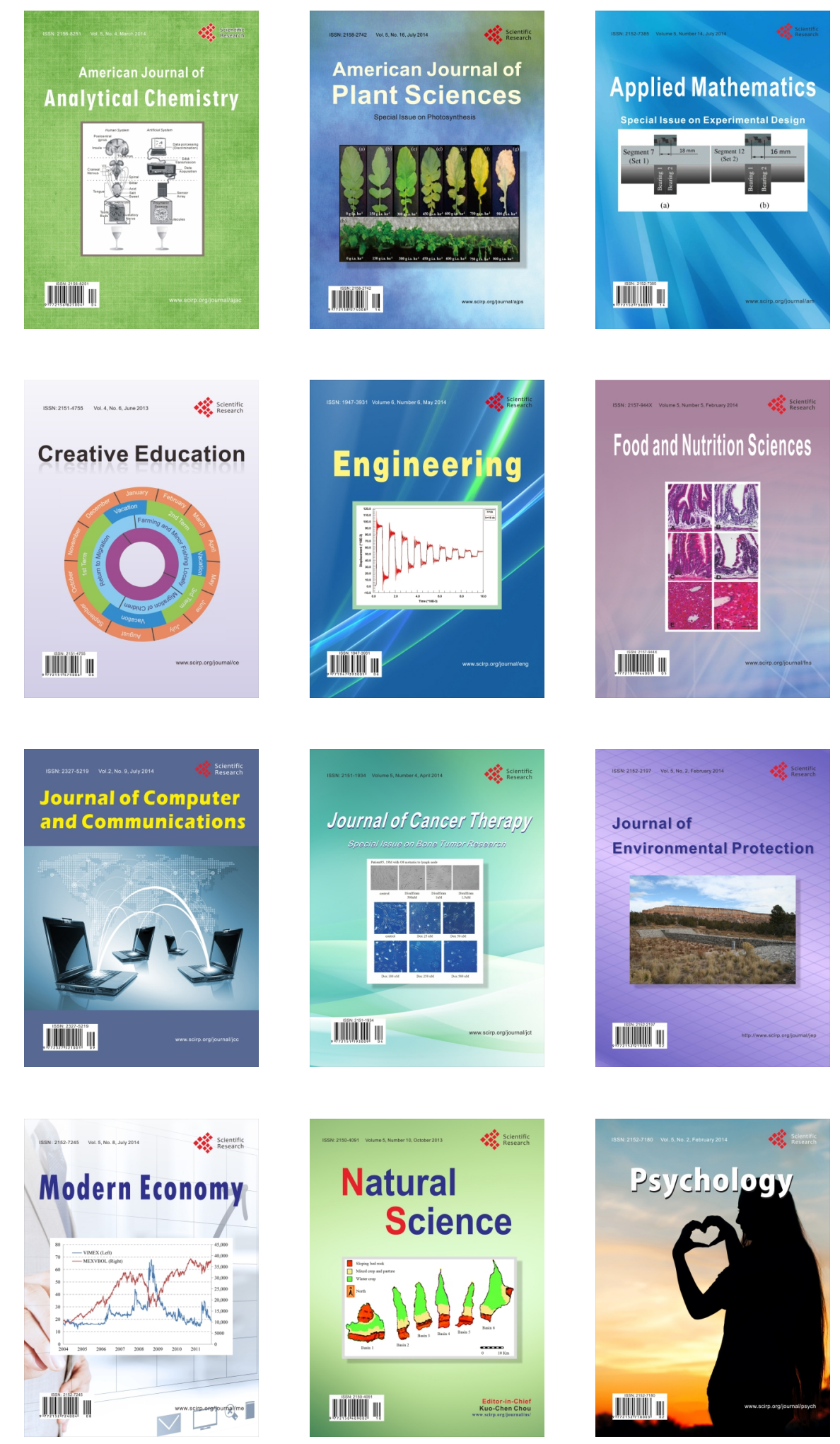